which can be learned from carefully structured, self-conscious, and intellectually-grounded experience.

\section{Notes}

${ }^{*}$ We would like to acknowledge Professor Emeritus Mavis Mann Reeves of the University of Maryland for her contributions this program and for her helpful comments on an earlier draft of this article.

1. The doctoral student participants in this program are referred to as "Fellows" to distinguish them-in skill level and focus-from the undergraduate and M.A.-level interns that abound in state and local government agencies, and particularly in state legislatures.

2. Of the five students in the program every year, from one to three have already earned their M.A.S.

3. Fellows are paid by the University, not by the office in which they are placed. Because the office does not have financial responsibility, the imperative to "responsibly" (e.g., fully) use the available talent may be minimized.

4. There is also a third option in which the Fellow works on a primary project and assumes additional staff responsibility. This approach has proven to be successful in allowing student both to have specific responsibilities and to be integrated into the organization. The caveat here concerns workload. Because the student has responsibilities that are not relevant to determining the workload of other staff members (e.g., coursework), the Fellow and the program director must take care to insure that the student will not be overloaded by responsibilities. A hybrid approach to onsite learning offers the most opportunity to the student, but it is likely to be a demanding experience, and must be carefully considered by all involved parties.

5. Which is not to say that tasks are not completed. Indeed, without exception, the Fellows have all accomplished the tasks set out in their discussions with their mentors, and have all received glowing on-site evaluations. Many have been asked to continue their duties for compensation after completing their Fellowships.

6. See Brace and Jewett (1995) for a fuller discussion of this literature.

7. Qualitative research is generally understood to mean "case studies." Indeed, the opportunity to develop any one of several different types of case studies (including the illustrative case study, the exploratory case study, and the program implementation and/or effects case study) is notable. See GAO (1990) for more on the various types of case studies. It should be noted, however, that experiential education also provides substantial opportunities for other types of qualitative research that may be useful to the political science researcher, including oral histories and ethnographies.

8. Research in state and local government has been particularly susceptible to these trends, as the "universe" of fifty states provides a substantial, yet manageable, amount of data on comparable phenomena (e.g., campaign spending) that are well-suited to this type of analysis. See Brace and Jewett (1995).

\section{References}

Bailey, Mary Timney. 1992. "Do Physicists Use Case Studies?" Public Administration Review 52:47-54.

Brace, Paul and Aubrey Jewett. 1995. "Field Essay: The State of Political Science Research." Political Research Quarterly 48: 623-41.

Government Accounting Office. 1990. Case Study Evaluations. Washington, DC: Government Printing Office.

Jones, Bryan. 1995. "Mindless Empiricism in the Theoretical Wasteland." PA Times 18(10): 27-29.

Kolb, Darl G. 1992. "The Practicality of Theory." Joumal of Experiential Education 15(2): $24-28$.

\section{About the Authors}

Vincent L. Marando is professor of government and politics at the University of Maryland, where he is also Director of the Graduate Public Service Fellowship Program. His research on intergovernmental public policy focuses on metropolitan governance and local government structural reform.

Mary Beth Melchior received her Ph.D. from the department of government and politics, University of Maryland, and was involved in the Graduate Public Service Fellowship Program in several different capacities. She is currently a visiting assistant professor at the University of Mississippi, teaching American politics and political theory.

\title{
A Dramaturgical Approach to Teaching Political Science
}

\author{
John F. Freie, LeMoyne College
}

\begin{abstract}
Only through art can we get outside of ourselves and know another's view of the universe and see landscapes which would otherwise have remained un-

known to us.
\end{abstract}

Marcel Proust, The Past Recaptured

Politics has become increasingly theatrical in modern America. While we may expect that during electoral campaigns candidates participate in a certain amount of "acting," it is now commonplace to view the dayto-day behavior of politicians in theatrical terms as they attempt to marshal public support for their ideas. What's more, the predominance of electronic journalism as the most used news source has placed an emphasis on the ability of leaders to create po- litical spectacles in order to obtain political support (Edelman 1988).

Although this article will describe dramaturgical techniques used in teaching a course on the American Presidency-perhaps the most highly visible public office-the applicability of this pedagogical approach is far broader. Whatever political arena is the subject of study, political actors put themselves before others in attempts to influence them. This is true not just in the external political realm, which is the subject of a course, but it is true of the internal workings of a course itself. Goffman's observation is true of all politics, that which is studied as well as that which occurs within the class- room: "When an individual plays a part he implicitly requests his observers to take seriously the impression that is fostered before them" $(1959,17)$.

The teaching approach described here is dramaturgical. It involves employing actions, scenes, agents, agency, and purpose to encourage students to both experience and analyze political behavior. The dramaturgical approach may be applied to many courses, but this article will describe how it has been used in one on the presidency. The presidency, with its emphasis on personality, conflict, and highly controlled staging of presidential appearance, lends itself easily to being taught and un- 
derstood through the dramaturgical approach.

The key to teaching dramaturgically is to reconceptualize the classroom in terms of its theatrical dimensions. In this vein, there is a stage (the classroom), a troupe of actors (some students), an audience (other students), a director (the professor), and a script (reading materials). It is the responsibility of the professor/director to create scenes in which the students/actors, following the readings/script, interact/act to create meanings which incorporate both the written text/script and the symbolic interactions of the students/ actors.

The purposes of this pedagogical strategy are multiple: to encourage student participation, to develop empathy for different points of view, to develop a capacity for dealing with ambiguity, to understand the use of symbolism in political life, to encourage examination of politically relevant behaviors commonly ignored, and to understand, through experience, how and why politicians act. The dramaturgical approach offers the possibility of matching the pedagogy of the course to the subject matter and, by doing so, enlivening the classroom.

For many students, participation in class is restricted either because they fear embarrassment or because the arrangement and operation of the class unconsciously discourages active involvement. The dramaturgical approach addresses both of these issues. Much like Harry the shy clerk and Helene, the young woman devoid of personality, in Vonnegut's short story "Who Am I This Time?" (1968) many students, liberated from the burden of "being themselves," become engaged in the class when they embrace a character everyone realizes is "not themselves." In addition, the entire theatrical setting of the classroom virtually compels students to participate. In a very real sense nothing will happen, no action will take place, unless the students become active participants.

Since artistic expression is composed of symbols, it is, by its very nature, subject to multiple interpretations and layered meanings. Some meanings incorporated into the same symbol may actually be contradictory.
This is, of course, a strength of artistic performance. Although symbolic expression is acknowledged by the initiator of the action as intentional, its strength lies in not revealing precisely what the intent is but, instead, in allowing all the possible meanings of the symbolic act to condense and, thereby, influence the audience. By taking symbolic actions and making verbal responses each student senses the power of the symbolic act and begins to understand the valid yet ambiguous nature of all political positions.

\section{The Cast: Students}

The first step in preparing students to assume their roles in the dramaturgical classroom is working with them to select roles they will play over the course of the semester. Each student selects a single role to play throughout the semester. The characters they choose should be in-depth portrayals where they become intimately conscious of the nature of their characters. Obviously, most courses will contain more students than characters. There is no problem in allowing some characters to be played by several students. In fact, this encourages them to work together outside of class to discuss their characters and how they should be played.

When setting up the course, the professor should sketch out a range of possible characters students may select to portray. Although the final selection of the particular character each student will play follows a meeting between the student and the professor, the range of types of characters will depend upon the subject matter of the course as well as the particular objectives the professor wishes to achieve. For example, in the course on the presidency where I have used this approach, my objectives were to show the dramaturgical nature of the presidency today, to broaden students' ideological range of thinking about politics, and to develop students' empathy for differing viewpoints. In addition, of course, I wanted to provide students with basic knowledge about, and insights into, the operation of the presidency itself. Designing the course with these objectives in mind,
I included the following characters: the liberal, the conservative, the fundamentalist Christian, the believer, the political psychologist, the '60s radical, the Marxist, the skeptic, the right-winger, the cynic, the pollyanna, and the theorist. Students playing these roles can easily respond to material on the topic while, at the same time, get a sense of how someone approaching the issue from a different perspective might feel about it.

In other courses, the cast of characters should be adapted to reflect the particular content and alternative themes. For example, in an international politics course, one might envision a dove, a hawk, a liberation theologist, and a third-world citizen, as well as the full troupe of ideological characters. In a public administration course, many of the characters used in the presidency list above might be included along with others which might be particularly well suited for the development of alternative approaches to administration such as the humanist, the brute empiricist, the consensus-builder, the popular democrat, and the like. While students should be encouraged to base their choice of roles upon their own understanding of their needs, interests, and daring, it is up to the professor to establish the entire cast of characters. Decisions of which students should play which roles-especially uncomfortable roles-must be based upon the specific content objectives of the professor, the theme of the course, and the extent to which the professor wishes to expand the range of the discussions and performances.

The roles are intended to be characterizations rather than social or occupational roles. For example, if one is a liberal one may, while remaining in character, play one of any variety of social or occupational roles-a president, a press reporter, a senator, or an average citizen. At the outset of the course a brief description of each character is provided for the students, but developing a more detailed character profile is the responsibility (and the first assignment) of the student.

Students are encouraged to select a character which appears to be as different from themselves as possi- 
ble. In other words, without making themselves uncomfortable, students are discouraged from merely "being themselves;" it is impressed upon them that one of the purposes of the course is to develop empathy for differences. Thus, a consciously conservative student might be encouraged to select the role of a liberal or leftist radical, a cynical student might be encouraged to embrace the role of a humanist. While most characters do not lend themselves well to possessing polar opposites, the objective should be to encourage students to adopt characters which touch upon undeveloped aspects of their own personalities. Still, it is important to not push students too far because they must have some experiential base from which to construct their character.

After selecting their character, each students' first assignment is to construct an essay which describes, as they envision them, the character they have chosen to portray. This requires research. Students are asked to describe their character's view of human nature and assumptions about human behavior, his or her politically relevant beliefs, how the character uses rhetoric, where the character would obtain his or her beliefs, what newspapers and magazines the character might regularly read, what television programs the character might watch, how the character would dress, how the character would relate to other characters, and the like. After students have written and submitted their character sketches, they are evaluated and suggestions for improvement are made. Students are encouraged to revise their sketches multiple times. It is important that they spend considerable time researching and preparing for the role they will play.

Once all students have selected a character and completed their first assignment, the drama begins. Unless there is a specified "role suspension day" all students/actors are to respond, once they enter the classroom, "in character." When in class, they are to "become" the character they have selected. When listening to others, when discussing material, when taking notes, they are to do so as if they were that person. The dramaturgical perspective asks that students be both intensely involved in revealing their character as well as detached enough to be able to calculate the impact of their behavior.

\section{The Director/Professor}

The professor assumes the role of director and creates environments/ scenes in which the students/actors may reveal their characters. The professor, in effect, sets the stage by selecting the reading materials which are appropriate (the script) and setting the environment/scene in which the action will take place. As in traditional classes, the professor is responsible for structuring a learning environment conducive to engaging students in learning.

One of the most important responsibilities of the professor/director is casting. As is true of a good play, matching each performer with the appropriate character is important for the overall success of the class. It is important for the professor to get to know the students as well as possible while attempting to work with each of them to identify the character which will challenge them, but also be feasible given the students' own personalities. This means that the class size must be relatively small (probably no more than 25) and that considerable time must be spent during the first weeks of the semester talking individually with each. In addition, working with the dramaturgical assistant (see below), the professor should, early on, make assessments about the ability of each student to successfully play the character chosen. Adjustments (whether changing characters or working more intensively with the dramaturgical assistant) should be made early in the semester.

Preparation for such a class obviously differs from preparation for the lecture/discussion classes most political scientists were trained to teach in graduate school. Mastery of the subject matter is a given, but it is not the primary focus of preparation. Instead, the professor must carefully select and assign readings which will allow the characters to be publicly revealed; he or she must also be constantly concerned with creating a classroom most appropriate for fully covering the desired topics.

Above all, the professor must make it clear to students how the goals and objectives of the course can be achieved by employing the dramaturgical approach. This cannot merely be done at the beginning of the course, but must be continually emphasized throughout the course.

\section{The Action}

Reading materials which take points of view or develop analytical frameworks (rather than traditional texts) work best to create action because they inherently involve conflicts, which are important elements in drama. It is possible to cover virtually every topic normally covered in a standard course using such material. There is no need to compromise content.

The creation of scenes is limited only by the creativity of the professor. A few examples drawn from the presidency course follow to illustrate what can be done. One scene that can easily be created is the presidential press conference. In conjunction with readings about the presidency and the press, a scene may be created in which one student/actor is selected to play the part of the president (from the perspective of his/her character), another is the press director, others are media advisors, and other students become reporters. To add a bit more realism, you may even add a video camera; the resulting tape can even be used in a later class for analysis. To illustrate how approaching things from different perspectives changes the nature of interactions, the same press conference may be played by switching characters into different roles (e.g., the president may be a liberal in one scene, a conservative in another, etc.). Choosing the subject matter for the press conference offers a further opportunity to inject additional content into the class. One might, for example, conduct a press conference on foreign policy, welfare reform, campaign financing, or other policies dependent on presidential input.

One can imagine similar scenes in other courses without too much difficulty. The UN Secretary General 
or the mayor of a city could hold a similar press conference, a prime minister could participate in a question and answer session in Parliament, an agency head could testify at a congressional committee hearing - the possibilities are endless. Whenever politicians present themselves in front of an audience, the possibility exists to apply a dramaturgical simulation. Those that work best involve controversial issues, allow for multiple interpretations, and allow the students/actors to reveal both the cognitive and the affective dimensions of their characters.

Some students will, of course, be reluctant to get involved. Activities can be created which help "break the ice" for them. One such activity is "the numbers game." In the numbers game, the topic to be discussed is identified, readings are assigned, and the discussion is initiated and controlled by the professor, who assigns each student a number and selects students to discuss at random by drawing numbered cards from a pile. When a student's number is selected he or she must contribute to the discussion as it is progressing from the vantage point of his or her character. This is only one of many different kinds of activities which can be used to overcome students' reluctance to speak in class.

The types of dramatic activities should vary throughout the semester to make it possible for students to add depth and range to their characters. A variety of activities will also help reveal the extent to which the students have mastered their characters. Obvious dramatic settings (e.g., press conferences, debates, congressional hearings, etc.) are often easier for most students to perform in than less dramatic settings (e.g., discussion of a reading) but both allow students to explore different dimensions of their characters.

\section{The Dramaturgical Assistant}

To help students improvise their characters, it is helpful to use a student with theatrical experience as an acting coach. I have been fortunate in being able to use students who were both political science majors and drama minors or who had performed in campus plays. After students select their characters, but before the first scene is performed, the dramaturgical assistant works with the students on impromptu acting. Thereafter, throughout the semester, the dramaturgical assistant works with students to assist them in mastering their roles, sometimes sitting with them in class and modeling their character for them, sometimes working with them outside of class, sometimes giving them small bits of advice or acting tips. In addition, the dramaturgical assistant meets with the professor on a regular basis to devise new activities, to help assess student performance, and to troubleshoot problems.

\section{Intermission}

The dramaturgical approach is an exacting experience for both the students and the professor. It is helpful to provide a variety of dramatic scenes, but it is also important to provide ample time during the semester when students are not performing. Role suspension days, class sessions during which students are not expected to be "in character," should be interspersed liberally throughout the term. These might be days when subjects thought not to be appropriate for dramaturgical presentation are introduced or they may be days when it is evident that the students need a break from performing.

Another time it might be wise to suspend performances is when the class will be used to examine the performances of political actors in a particular situation. For example, in the presidency course, excerpts from presidential debates might be viewed, examined, and discussed in class in order to show students the dramatic nature of presidential behavior and to provide them with additional acting insights. These sessions may also be used to prepare students for upcoming scenes. For example, prior to the presidential press conference, it is helpful to actually view and analyze a real press conference. Finally, there should be time set aside for students to discuss and analyze their own performances.
This need not take an entire class session, but the students should be given enough time to give and receive feedback about what works and what doesn't and make suggestions about changes in the format.

\section{Reviews}

Evaluation of students' performances obviously falls within the scope of the professor's responsibilities. A variety of mechanisms may be used to evaluate performances. Some may be closely tied to the students' dramaturgical activities while others may have little or nothing to do with them, focusing instead on the content of the course. I have found it helpful to create an evaluation scheme which assesses both aspects of students' development. As already discussed, the students' first assignment is developing an extensive written description and analysis of the characters they have selected.

Students also submit a series of short analytical papers (written from the perspective of the student's character) which are used to assess the students' abilities to understand and articulate positions they do not personally hold. Sometimes these analytic papers include a "response" section where students present their own views.

More traditional forms of evaluation, such as standardized tests or essay exams, can be used to assess the students' mastery of the subject matter. These exams follow traditional formats and students are not "in character" when taking them. I have also found it helpful to require students to prepare self evaluations as a final written activity. In conducting the self evaluations, students are asked to review their performances and reflect upon the effectiveness of the dramaturgical perspective as a method of learning about the presidency and about themselves as political actors.

Obviously, other evaluation methods may also be used to assess performance and mastery of the subject matter. Whatever activities are chosen, they should encourage students to reflect upon their dramatic performances and see their actions as political in nature. 


\section{Final Curtain}

The dramaturgical approach to teaching reconstructs the traditional classroom and transforms it, changing it from a predictable, fixed environment into a complex, multilayered environment where even the most apparent truths may be subject to scrutiny. It exploits the benefits of the artistic perspective to cast light upon politics and foster learning. "Artistic performances generate tensions which we can resolve only by becoming alive to new ways of viewing the world. They detach us from old ways. They change our loyalties. De-eroticizing our old involvements, they alienate us from whatever objectives we have embraced with singular intensity" (Kariel 1977, 61). The dramaturgical approach encourages student involvement, challenges assumptions about teaching, and provides an alternative model for understanding political behavior.
Fully implementing the dramaturgical approach requires considerable effort on the part of the professor and the students. In addition, it requires support from administrators who are willing to stand behind teachers who wish to innovate in the classroom. But aside from issues of time, energy, and support, political science professors must be open to new ways of approaching old subjects if they wish to enliven the subject matter and the classroom.

\section{References}

Edelman, Murray. 1988. Constructing the Political Spectacle. Chicago: University of Chicago Press.

Goffman, Erving. 1959. The Presentation of Self in Everyday Society. Garden City, NY: Doubleday Anchor Books.

Kariel, Henry S. 1977. Beyond Liberalism,

\title{
Learning Styles of Political Science Students
}

\author{
Richard L. Fox, Union College \\ Shirley A. Ronkowski, University of California, Santa Barbara
}

The perennial struggle to reach out to our students and engage their minds is something that plagues all college and university faculty. Political science instructors may have a slight advantage over instructors in other fields in connecting with students since our subject matter focuses on clashing ideas which can directly affect the lives of our students. Nonetheless, the teaching of political science presents many of the same dilemmas faced by instructors in every discipline. We want to bring theoretical material to life for students, choose case studies relevant to their lives, and excite them about the important questions in our respective fields. Our angst and frustration over our teaching almost always seem to focus on changing instructor style and technique. Should I change the format of the class? Should I revise the assignments? Should I change my method of presentation? By asking ourselves only these questions, we overlook the variety of ways in which students conceptualize and process information and ideas. Understanding various student learning styles can be helpful in designing instruction that engages students by appealing to their particular learning abilities. In the present analysis we will examine the learning profiles of students in political science courses at a private liberal arts college. Our underlying assumption is that the more we know about our students and their learning styles, the better we will be able to design instruction that allows students to make use of their strengths and not be unduly hampered by their learning weaknesses.

\section{Method of This Study}

Student learning styles and preferences have been extensively studied, and many types of learning style
Where Relations Grow. San Francisco: Chandler \& Sharp Publishers.

Vonnegut, Kurt. 1968. "Who Am I This Time?" In Welcome to the Monkeyhouse. NY: Delacorte Press.

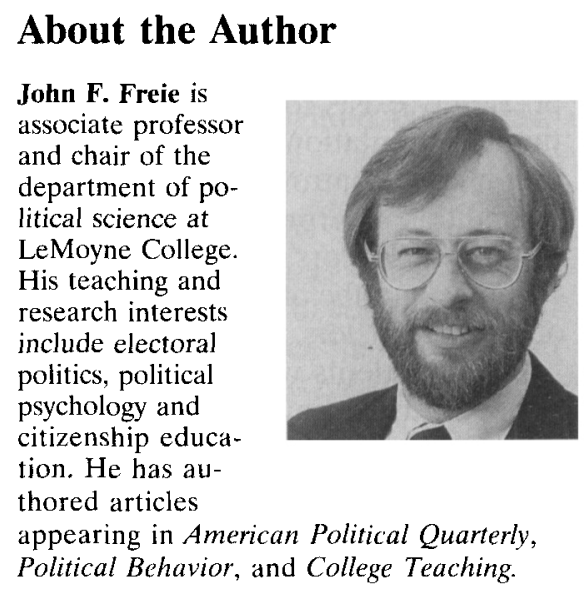

John F. Freie is associate professor and chair of the department of political science at LeMoyne College. His teaching and research interests include electoral politics, political psychology and citizenship educathored articles Political Behavior, and College Teaching. models have been developed. Various models and accompanying inventories have been designed and classified based on one of three preference areas: information processing, environmental, and personality related (Hickcox 1995). The information processing model developed by David Kolb $(1984,1985)$ is the one we favor, having used it successfully over the past six years in our own teaching. Kolb's Experiential Learning Cycle, and accompanying Learning Style Inventory (LSI), have been extensively analyzed, tested, and critiqued as evidenced by the 679 citations of Kolb's work listed in the Social Sciences Citation Index between 1971 and 1989 (Hickcox 1991, 4). The majority of these studies and critiques, particularly those focused on the LSI in higher education, give positive support; "criticisms usually center on psychometric issues, and it should be noted that even the most critical studies of 